\title{
Understanding International Conflict: Some Theoretical Gaps
}

\author{
MIROSLAV NINCIC \\ University of Michigan
}

\begin{abstract}
The purpose here is to consider some significant gaps in the theoretical bases with which we seek to understand international conflict - either at the level of non-military hostility or at that of actual warfare. The incentives behind both levels of conflictive behavior are examined in terms of discrepancies between achieved and expected levels of attainment (attainment gaps) on relevant needs. Two general conflict-inducing situations at the level of non-violent hostility are identified: one where the attainment gap is causally attributable to the target of the hostility and another where such behavior might help narrow the gap even in the absence of external attributability. Although the properties of a nation which, in the second situation, might make it the object of another's hostility are not well understood, some tentative suggestions are advanced to account for this possibility. The differences in the incentives behind warfare and those that lead to simple hostility are considered, with particular attention to the relation between specific sorts of unsatisfied needs and war involvement. It is suggested that both the salience of certain needs and the range of strategies to enhance attainments thereon are factors which link given needs to armed conflict; both, it is argued, are shaped by the nature and structure of the societies within which the needs are experienced. Situations where the benefits from simple hostility carry over into (or are amplified by) warfare are discussed, as are instances where the contrary occurs. Tentative explanations for these patterns are suggested. Finally, the impact of military capacity on the transition from hostility to warfare is examined, both from the point of view of the balance between potential antagonists and the nature of the actual weaponry involved.
\end{abstract}

There is currently no dearth of writing and research on the correlates, causes, and even consequences, of international conflict. A fair amount of data has been generated, statistical correlations produced, and partial increments to scientific knowledge claimed.' From abstract speculation guided by a combination of historical insight and theoretical intuition, we have moved in the direction of manifest empiricism. Despite the tenacity and vigor of our efforts we seem at best to be languidly scudding toward cumulative knowledge. Research findings and substantive understanding are simply not moving in tandem, and it could be that our ability to systematize these findings, and to place them in a relevant theoretical context, have not kept pace with the evolving technology of research. It should not be assumed that a fully developed theoretical structure must necessarily precede research. In the absence of axiomatic observations from which to inferentially derive analytical propositions, then to be subjected to empirical confirmation or disconfirmation, research and theory building should be intertwined at every stage. Currently, however, the former seems to be insufficiently informed by the latter, and what we need at this point is, at the very least, a backdrop of useful questions, concepts, and relational hypotheses, against which the morass of extant empirical findings could be evaluated and which might, furthermore, beneficially guide subsequent research. I will try to make some suggestions in this vein by focusing primarily on issues which do not seem to have claimed sufficient attention. The fact that some of these issues are rather elementary underscores the need to address them more fully.

The concern here is with international conflict, i.e. with that class of external behavior where efforts to impose costs on others dominate attempts at achieving cooperative gains. This need not involve armed violence, as such costs can be imposed in various ways and imply deprivations of different sorts and magnitudes. Let us then distinguish two categories of international conflict: one involving armed violence (i.e. warfare) and another where costs are imposed short of military means (and termed simply hostility). It may be useful to view these as two major segments along a 
continuum of increasingly conflictive external behavior rather than as qualitatively different categories. While the ultimate concern here will be with warfare, the nature of the causal mechanisms behind the two is often not substantially different. Additional variables may be needed to account for violence or the same variables might have to assume values in different ranges, but the causes of warfare may frequently be subsumed within those of hostility. In other words, one could not usually provide an adequate account of the reasons for the onset of war $^{2}$ without explaining why there would, in any case, have been hostility but why, due to additional considerations, conflict did in fact assume a violent form. I will proceed accordingly. The structure of the incentives behind conflictive behavior will be discussed by focusing, first of all, on hostility, and two elementary situations, associated with quite different causal mechanisms, will be briefly discussed. Following this, the circumstances which may lead governments to engage in actual warfare rather than to limit their conflict to simple hostility will be examined. In this context, the role of military power and of the changing instruments of warfare will be considered.

International conflict can be analyzed at a variety of levels. One can focus on the structure of the international system and search for roles, interactions, and ways of distributing economic and symbolic goods which seem to have a bearing on hostility or warfare. One could do as much for dyads of nations or one could place the emphasis on the goals, capabilities, and habits of individual states. At an even greater level of specificity, the interests and power of subnational groups and institutions could be subjected to intense scrutiny. Some eclecticism is certainly possible here, and choices will depend on the uses to which the knowledge is to be put and on the nature of the questions to which answers are sought. Here we will settle for an intermediate level of generality by making the nation-state our principal unit of analysis. Let us begin then with hostile behavior and attempt to get a grip on the incentives from which it springs.

\section{The structure of hostility}

The concern here will be with purposeful foreign policy behavior, implying that there is a conscious link, in the policy makers' minds, between the behavior and the attainment of some desired end-state. As long as external hostility is purposeful it is likely to stem from some dissatisfaction ${ }^{3}$ generated by a discrepancy between achievements and desires i.e., from an attainment-gap on some need pursued by the authorities who make decisions on behalf of the nation. In addition, there must be some perceived reason indicating that hostility will contribute to its reduction. A starting point, therefore, is provided by the concept of needs with respect to which attainment gaps can be experienced.

At an earlier stage in the development of the discipline, it was generally assumed that the quest for national power, a need with zero-sum implications and one which every nation was to experience uniformly, ${ }^{4}$ provided the incentive behind all international conflict. Tautologies implied by extreme versions of this paradigm have been adequately exposed and, though power is clearly instrumental to the attainment of a wide variety of ends in foreign policy, a more nuanced view of ultimate needs is called for. It is, of course, virtually impossible to provide an exhaustive inventory of the goals pursued by governments and on which foreign policies might bear. Nor would this be a particularly useful exercise as variations in goals exist both between societies and within the same societies across time. At some level of abstraction a taxonomy can nevertheless be quite useful and a reasonable balance between comprehensiveness and parsimony might be provided by the following set of five needs: (1) regime security (the stability of the basic rules governing the polity and society), (2) national security (safety of territory and population from external threats), (3) the political authorities' own continued incumbency, (4) national prosperity, and, (5) national prestige (the symbolic rewards bestowed on the nation from outside). These needs will never be quite independent, nor are they all equally salient in all nations and at all 
times; nonetheless, all are likely to be important to governments and each can, under certain conditions, be affected by external conflict.

By definition, the size of an attainment gap for a nation (a) is given by:

$\operatorname{GAP}_{\mathrm{a}}^{\mathrm{i}}=\left(\mathrm{E}_{\mathrm{i}}-\mathrm{A}_{\mathrm{i}}\right)_{\mathrm{a}}$, where,

$E_{1}:$ is the expected level of attainment for the nation on need $i$, that which it was considered possible, and hence desirable, to attain.

$A_{i}:$ is the actual level of attainment of (a) on (i).

While the actual level of attainment is directly given, expectations can be determined in a variety of ways depending on the sort of referent value of attainment which is most important in establishing expectations. A fairly large body of literature has dealt with this issue and, within it, several conceptions of the most significant such referent can be distinguished. While these writings are for the most part sociological, applications to international relations are quite straightforward.

According to one perspective, expectations are formed on the basis of achievements of salient reference groups to which one's own attainments are compared. The larger the gap between the two, the greater the dissatisfaction and the stronger is the incentive to do something about it. It is sometimes assumed that the tendency to compare increases as the overall social distance between an actor and a prospective reference group decreases - the implication being that important gaps are those engendered by a failure to achieve that which seems to be within reasonable grasp. ${ }^{5}$ In other words, while Argentina might compare itself to Brazil or Pakistan to India, neither would be likely to choose a major industrial power as a natural standard for comparison.

Another school of thought views 'status disequilibrium' - a lack of consistency in levels of achievement on salient needs - as particularly important. A discrepancy, for example, between prestige and prosperity could induce a nation to seek to do better on the need with respect to which attainments are lagging. Occasionally, disequilibria of this sort have been directly linked to aggressive behavior. $^{6}$

A third perspective suggests that it is past performance which defines the trend along which present achievements are expected to progress. If current attainments are below the level predicted by the trend, dissatisfaction will ensue. ${ }^{7}$ For example, as Soviet economic growth rates dip below the figures of previous decades, an increasing amount of perceived deprivation could be anticipated.

Although it is habitual in the social sciences to think in terms of relative deprivation (where the value of the referent, while given by an explicit rule, is specific to each actor), it should be useful to conceive of a constant referent value for all actors as well. Attainment gaps are then no longer relative but, in terms of measurement procedure, absolute. In this case one would usually (though not necessarily) take a zero level of attainment as a referent. ${ }^{8}$

Thus there are at least four types of deprivation which could lead a nation to undertake some corrective behavior. It is, however, worth pointing out that the mere existence of an attainment gap should not, per se, cause hostile foreign policy behavior. All that can be assumed, in the absence of additional considerations, is that it will provide a drive toward some sort of action. These policies, in the case of the behavior of states, might be directed at the domestic context without involving other nations and, even if they were involved, the externally directed behavior would not inevitably be hostile (cooperative behavior might be more apposite to the situation). Where then are we to seek these additional considerations?

A first suggestion might be that some specific type of gap makes hostility against another nation particularly likely. A frequent belief, for example, is that this sort of behavior occurs when the feeling of deprivation stems from an unfavorable comparison with another nation. While it is unlikely that invidious 
comparisons are drawn on the basis of national and regime security or the security of the political authorities' own incumbency (absolute attainments are what matter in these instances), they could be made for economic prosperity and prestige which can be reasonably assessed only in relative terms. This would be hostility born of simple jealousy and induced by the nature of the referent used in appraising performance. Still, historical instances of so simple a situation are scarce and in many instances, perhaps most, it might be irrelevant whether a gap is based on a comparison with past performance, another nation, discrepant attainments on different needs, or some absolute failure. It could be argued that the nature of the referent chosen as a standard of achievement is less crucial to explaining hostility than is the type of need which is involved in the gap. It is this which defines the aims and the stakes of the hostile behavior but, despite the intuitive salience of this type of consideration, its relevance has by no means been established. The issue will be addressed again in the discussion of warfare and, while there may be reason to believe that states are more likely to engage in armed conflict over certain aims than over others, there little empirical evidence, and no sound theoretical foundation, for believing that hostility of a nonviolent sort is systematically related to deprivations concerning specific needs.

It may be necessary to look further and to cast the explanatory net outside of the gap itself. What might often be very significant is whether one's own inadequate attainments are causally attributed to the activities of another nation. If so, hostility would be the product of resentment and the responsible party would be its target. There may even be several nations to whom responsibility is imputed and, hence, multiple targets. A few examples will illustrate this first type of drive toward external hostility.

A prosperous nation which is excluded from major international councils, or denied a symbol of national prestige (e.g., a nuclear weapon), might feel slighted in terms of the status to which it considers that its wealth should entitle it. Hostility toward those held responsible for such a situation would be a likely response. Examples of this sort are by no means rare. Germany's economic growth from the late nineteenth century to the first decades of the twentieth was not translated into corresponding status and a major international role. A lack of colonies at the beginning of the century and the humiliation of Versailles surely go a long way toward explaining a pattern of aggressivity which produced two of history's most destructive wars. Economic deprivation, on the other hand, will often generate animosity toward those whose prosperity is being achieved at one's expense. The 'beggar my neighbor' policies associated with the depression of the thirties bear some of the onus for the international tension and distrust of the period.

There is, therefore, reason to assume that the causal attributility of attainment gaps is a condition of international conflict and that the spatial or temporal frequency of such behavior reflects the extent to which national interests are perceived as incompatible. If attributibility is, indeed, a fulcrum around which commitment to hostility frequently revolves, an understanding of perceptions of causality should be a significant concern of peace research, and one which is partly independent of the quest for patterns of empirical causality (i.e., those which transpire from observers' estimates of causal regularities among events, trends or structures). A concern with perceptions should by no means supplant an interest in the objective facts of the situation, rather it should supplement it by enlightening us not only as to why certain nations may be made to suffer by others, but why this will sometimes be recognized, sometimes not, and occasionally wrongly assumed. Not only would it be useful to grasp the manner in which governments, under various circumstances, attribute responsibility for their nation's performance to others, but also to understand how they convey their perceptions, and with what effect, to the domestic environment, whose support for conflictive foreign policies must be sought. We know surprisingly little of these 
matters, and efforts at remedying these deficiencies appear scant. Still, causal accountability for attainment gaps does not provide the only context from which external hostility might stem; to distinguish it from a rather different situation, I will call it the Type 1 situation. In this instance, both hostility and its target are determined by the link between the latter and the attainment gap. But hostility toward another may arise, not because that nation is in any way accountable for the deprivation, but because such behavior might nevertheless reduce the gap due to some attribute of the target's. It is not the conduct of the target which matters here so much as its nature. We will term this a Type 2 situation and illustrate it with an example.

According to one line of reasoning, threats to governments can often be mitigated by invoking or provoking external hostility. The idea is that attention can often be deflected from unsolved domestic problems and a climate of solidarity with the regime and incumbent political authorities created. In addition, hostility may provide the justification for an extension of formal govermental authority. This position, derived initially from the sociological theories of Simmel and Coser ${ }^{9}$, has found considerable acceptance among scholars $^{10}$ and one is reminded of the advice given by Henry IV on his deathbed to his son on the need to 'busy giddy minds with foreign quarrels'. But what will determine to whom the hostility is directed in a Type 2 situation? While the target may be blamed for a variety of the nation's difficulties, it would not in this case be an accusation which its own authors really believed. What then is most relevant to the choice? There is a dearth of both theoretical efforts and of empirical research on this question but at a rough and general level, and in order to open a discussion on the topic, two conditions for a potential target can be suggested. In the first place, it should be a nation with which politically significant domestic groups identify as little as possible. Otherwise the results could be counterproductive for security - certainly for the security of the incumbents and possibly for that of the regime as well. Secondly, the butt of the hostility should have attributes which make it sufficiently salient and visible to the domestic public. It is unlikely, in other words, that the government of Ethiopia could create much of a domestic impact by being bellicose to, for example, Paraguay. Nor would it be particularly useful for political authorities in, say, El Salvador to pick a quarrel with Iran.

Thus, there are at least two general situations (identified here as Type 1 and Type 2) in which external hostility can take root. Though the nature of the attainment gap will rarely, in and of itself, suffice to produce this behavior, it may be enough that the deprivation is imputable to another nation or that some property of the target should commend hostility as a promising path to gap reduction. But our understanding of the process of such imputation in the first situation, and our grasp of the properties which must characterize the target in the second situation, leave very much room for additional thought and research. If these matters seem obvious and elementary then the lacunae should be all the more glaring. Since, moreover, the structure of the incentives behind hostility provides part of the explanatory context needed to understand warfare, our comprehension of the most pernicious form of international hostility would benefit from such efforts. As pointed out at the beginning of this essay, our principal concern here is, in any case, with this highest level of conflict.

\section{Hostility or warfare?}

Assuming that a drive to some level of conflict is provided by either a Type 1 or a Type 2 situation, when will it produce warfare rather than hostility? We are not treading on entirely virgin territory here and there is a solid body of research dealing with the dynamics of crisis behavior: notably with the process whereby conflicts generate self-amplifying drives which may push both parties further up the escalatory ladder than either had initially planned to venture. However, the purpose here is not to survey that which we know rather well but, as 
explained at the outset, to identify areas which have been given rather short shrift by scholars.

One potentially important issue concerns the nature of the unsatisfied needs which most powerfully impel nations to external violence and which provide the stakes of warfare. While we know little on this matter, much is often vigorously claimed and, here, ideological inclinations are often the best predictors of opinions - with the political left emphasizing the importance of economic goals and conservatives typically claiming causal primacy for political issues. The evidence for either point of view has proven inconclusive, a fact which is scarcely surprising given the functional complexity of modern societies which makes it difficult to do as much as, say, sort out primary and instrumental goals. The role of various needs is, however, a matter about which we should know considerably more and the fundamental question is whether certain needs are particulary well served by warfare and, if so, what accounts for the fact that they are? Let us begin with the Type 1 situation.

External attributability for attainment gaps typically stems from the pursuit, by the target, of goals which are incompatible with those of the other side. Warfare would then be chosen if other ways of inducing the antagonist to abandon the pursuit of the incompatible goals are unavailable or are considered likely to be ineffective. Furthermore, these goals should be of substantial importance to both parties if they are to absorb the cost of armed belligerence in their pursuit. Thus, the salience of the need and the range of strategies for enhancing attainments on it seem to be the major factors linking certain needs to war. Both of these considerations, moreover, are almost certainly associated with nature and structure of the societies within which the needs are experienced. As the nature and structure of societies and of their international environment change, so do the warinducing needs. In sixteenth and seventeenth century Europe, for example, conflicts were frequently fought over religious issues. Mo- narchical disputes and matters of territorial control characterized warfare in the eighteen century. In the nineteenth century, nationalism inspired some major wars as did incompatibilities of ideology (primarily on the issue of republican versus monarchical forms of political organization) and of external economic interests. And so forth. Thus, while it may be fruitless to search for a link between certain needs and warfare independently of social context, this link could become apparent if this context were adequately taken into account. Certain societies will generate incompatibilities between certain goals and pursuits rather than between others, and thus make wars born of certain Type 1 situations particularly likely. The relationship is no doubt complex, and a pattern as simple as that suggested by radical or conservative purists should not be expected, but the significance of the issue to peace theory should be as evident as is the paucity and shallowness of our current knowledge on such matters.

There may be some properties of certain needs that make warfare (rather than mere hostility) more likely in a Type 2 situation as well, but this too is hard to separate from the societal context in which the need is being pursued. For example, if an economy needed bolstering via an expansion of public outlays (say to compensate for lethargic public investment), while the society's value system condemned governmental meddling in economic mechanisms, the invocation of a dire military need might be the only way of circumventing strong ideological opposition. In other words, there may be something about the relation between needs and societies which, in a Type 2 situation as well, might make war more likely than would otherwise be the case. But here our factual knowledge and theoretical understanding are as feeble as in the previous case suggesting vast, uncharted, and promising areas into which peace research could venture.

At this point the analyst should be wary of a potential pitfall. It is easy to assume that if simple hostility is of some use in narrowing attainment gaps, then armed violence (the 
higher level of conflict) should do an even better job. This however, may be a very mistaken assumption and a few examples should support the point.

It was suggested earlier that a government which was faced with domestic instability might initiate external hostility with the idea of focusing attention elsewhere and creating a 'rally around the flag' effect to its benefit. Grievances would be forgotten as the public rushed to support what appeared to be an overriding national cause and, if this willingness was not sufficiently in evidence, the authorities would at least have an excuse for tightening the reins of control at home (e.g., by imposing martial law). Yet, results which could be produced by hostility short of warfare might, under certain circumstances, be reversed if armed violence occurred. Substantial human losses and material sacrifices could cause a support which would have been granted a government were it merely rattling sabres and hurling invective abroad, to be withdrawn. In a similar vein, a nation experiencing severe ethnolinguistic rift could, perhaps, alleviate the problem by generating a foreign threat; but, with actual warfare, there is a danger that the enemy might provide side payments to the dissatisfied group to ensure its neutrality (and possibly even collaboration) thus exacerbating rather than mitigating the cleavage.

As a second sort of example: it is sometimes claimed that market economies, left to their own devices, would usually not manage to generate sufficient consumer and investor demand to match overall productive capacity (the Keynesian's issue of 'aggregate demand' and the radicals' problem of 'absorptive capacity'). This implies that public spending must fill the gap, something which can be effectively accomplished by military purchases which are justified, in turn, by existing hostilities. If, however, armed belligerence were involved, military demand could no longer be tuned to economic needs but would be dictated by the dynamics and requirements of the conflict itself. Substantial inflationary pressures are a typical result. Moreover, the need to maxi- mize current production in wartime usually means that insufficient resources will be devoted to maintaining existing capital stock and that new capital formation will be sluggish. As military outlays increase, investments must suffer and future economic performance may be seriously jeopardized.

In these two examples, hostility proved far more useful to reducing attainment gaps than was outright warfare, but this may not always be the case. As a third example, we might assume a society whose volume of material needs outstrips the economy's resource base causing various forms of deprivation. Ensuing socio-political disruptions could threaten the security of the regime and lead the government to seek to mitigate the instability by means of a well chosen foreign quarrel. Simple hostility might indeed produce the desired effect, but a more substantial and long term solution could at times be produced if access to neeeded resources abroad was ensured by military force; ${ }^{11}$ if so, the higher level of conflict would yield the more beneficial effect.

The conclusion which the three examples suggest for peace research is that more effort should be devoted to distinguishing the effects of the two levels of conflict, under various conditions, on enhanced attainments. While an extensive discussion is not within the compass of this essay, certain crude hypotheses can perhaps be drawn even on the limited basis of these examples. Specifically, if we assume that simple hostility would indeed have been beneficial, several possibilities are open for warfare.

It may be, as in the first two examples, that while hostility could be beneficial, its helpful effects simply do not carry over into violent conflict (which could actually produce highly detrimental effects). It is worth noting that in both instances the incentive to conflictive behavior, at the level of hostility as well as warfare, involved a Type 2 situation - one where the target could not be considered causally responsible for the nation's problem. In the third example, however, warfare could be more useful than hostility - not by trying to replicate or amplify the nature of the effects 
produced by the lower level of conflict (i.e., pacifying the public with external disputes), but by acquiring economic resources through force to some other nation's detriment (an entirely different sort of enterprise). The target of military coercion in this case could be altogether distinct from the one which would have been chosen as the object of mere hostility and is distinguished by the incompatibility between its immediate interests and those of the aggressor (the resources claimed by one side are unavailable to satisfy the needs of the other). Thus, the benefits of warfare in this instance are placed in the context of a Type 1 situation. Finally, and the reader can easily furnish his own example, it may be that the target is accountable for the aggressor's deprivation and that this could be mitigated by either hostility (e.g., threats) or warfare designed to force it to cease the objectionable behavior or to foresake the incompatible need.

What we may be discerning therefore is a world where the payoffs from hostility will extend to warfare as long as both levels of conflict involve external accountability for the gap. If, on the other hand, a Type 2 context provides the benefits at the level of hostility, they may not be replicated with armed violence. If this more serious form of conflict is to be beneficial as well, the nature of the game might have to change so as, once again, to involve a Type 1 situation (as in the third example). All of this, of course, is both roughly reasoned and based on examples which suggested themselves to the author (a fragile empirical foundation for general conclusions). My purpose, however, is to be suggestive rather than conclusive, to nudge peace researchers into considering these questions with both theoretical sensitivity and scientific rigor.

Of course, once conflictive behavior at any level comes to dominate a nation's foreign policy, further escalation may not be a matter of this kind of decisional calculus at all. Once embarked upon, such behavior can assume the form (as pointed out above, p. 43) of a self-amplifying feedback process where the dynamics of conflict override rational calcula- tions of the ultimate effects of the behavior. We grasp this rather well and have studied the matter fairly conscientiously. However, we should not allow our appreciation of such forces to blur the possibility that decision makers may not always be the victims of powerful dynamics over which they have lost control and, if we do accept this possibility, we should also strive to improve our understanding of the effects which different levels of conflict may produce on significant needs.

\section{Arms and war}

No decision concerning a specific course of action can be adequately understood solely by considering the drives behind the contemplated behavior. Every activity involves certain direct and anticipated costs which will be included in the decision makers' reckoning particularly when, as in the case of warfare, they are likely to be quite high. The extent of these costs, moreover, is in many ways contingent on the military might of the aggressor relative to that of the victim, and it is here that the concept of power is usually thought to be most significant. To begin with, the greater this ratio, the less the expected resistance of the target when changes in its behavior are sought through force. Even when one is dealing with a Type 2 situation, the desired domestic effects of warfare can be offset by its costs (as in our first two examples in that area) unless they are minimized by a coercive advantage. Relative military capacity is then one key to predicting whether the benefits of hostility may, after all, extend to armed confrontations.

It could be concluded that the greater the military advantage of the side with the conflictive drive, the more likely will it be to choose the road of warfare over that of hostility. But things are less simple than this, and the inference could frequently be misleading. The point is that a large advantage in military power may often render its actual exercise unnecessary. For example, in the case of incompatible national interests, the more powerful nation may be able to get its way sim- 
ply by threats made sufficiently intimidating by overhelming force. Thus, it may be that neither nearly equal, nor vastly discrepant, military power are particularly conducive to belligerence. The first situation makes it too risky, the second may render it superfluous. If armed conflict should nevertheless occur under conditions of near equality or vast discrepancy it would probably be because other considerations (e.g., the magnitude of the attainment gap) were particularly weighty for at least one of the parties.

Despite the attention that relative capacity has received at the hands of political scientists and historians, ${ }^{12}$ it may not be the only relevant aspect of the antagonists' military power. Its nature may actually be more important than the extent to which the aggregates are balanced - particularly when this nature reflects the ability of the weaponry to either decrease the vulnerability of one's own military or civilian installations or else to increase the vulnerability of those of the adversary. An emphasis on the former makes the military capacity essentially defensive, an emphasis on the latter confers an offensive character on it. It has been historically documented that offensive forces are more conducive to warfare than are those of a defensive nature. When offensive weaponry dominates the force posture of both sides, conflict is most likely to assume a violent form; but where both sides take on a defensive posture the prospects for peace are most favorable. ${ }^{13}$ This aspect of the issue has not been entirely neglected in the literature on peace and conflict, but it does not seem to have been granted nearly as much attention as have considerations of the conceptually rougher 'balance of power' sort.

In the more recent phases of the nuclear age, the distinction between offensive and defensive weapons has been supplemented by a distinction of a related but different kind. While there has been some toying with the idea of reducing national vulnerability to a nuclear assault by, say, A.B.M.s or fallout shelters, meaningful defenses against such a threat have simply not evolved. While the traditional military dichotomy has found little application in the nuclear age, a more apposite distinction separates first-strike and warfighting weapons from those with an essentially deterrent role. These two sets of functions are, in turn, defined by the type of target the weapon is designed to destroy - specifically whether this is a civilian target (e.g., an urban area or civilian installation) or one of a predominantly military character (such as a missile silo, command post or radar). In the first case, we would be dealing with what is termed a countervalue weapon, in the second case it would defined as counterforce. And, much as the offensive or defensive nature of force postures may have helped determine the likelihood of conventional wars, so does the counterforce-countervalue distinction appear to have such a function in the nuclear context. Barring a totally depraved of demented leadership, it can be assumed that the purpose of countervalue nuclear systems is to retaliate in the event of an attack, which implies that their main function is to deter an assault rather than to either inflict one or to ward off one which has been undertaken. Counterforce weapons, on the other hand, are best suited to impose a disabling first strike or to exchange targets in a limited nuclear conflict - i.e., to wage rather than to deter such a war.

The first kind of function has traditionally been central to superpower strategic doctrine which was based on the notion that a war between the two giants could best be avoided if each maintained the ability to absorb a firststrike and inflict, with its remaining forces, a level of countervalue destruction on the assailant that the latter would consider unacceptable. Under these circumstances, neither side would hazard an attack and peace would be maintained through the deterrent qualities of nuclear arsenals. Equality of military power was less relevant to war-avoidance than was the ability of each side to impose a specified but unacceptable level of retaliatory destruction on the initiator of the exchange. This was, of course, a new situation made possible by the technology of nuclear destruction. As George Quester has pointed out: 
In the past, one had first to defeat an enemy army before slaughtering his people. If one had that army on the run, one could at least be assured that no such slaughter would occur in reverse. The nuclear weapon delivered by airplane or rocket however lets a defeated government kill large numbers of the enemy's population even in the last days or hours of the war. ${ }^{19}$

Technology, however, does not stand still and recent developments have undermined the foundations of the traditional doctrine of deterrence by making unacceptable retaliatory damage no longer inevitable for an attacker. In particular, the increased accuracy of strategic and tactical weapons, as well as the expanding number of warheads (occasioned mainly by MIRVs), have made a disabling first-strike less and less inconceivable. Thus, the incentive to launch a preemptive strike in a crisis may grow and increase the likelihood of nuclear war. ${ }^{15}$

Among non-nuclear countries, this logic has never applied and the offensive-defensive dichotomy has remained quite applicable. But as increasingly destructive technology becomes available to more and more nations, the situation of the superpowers may become quite generalized. Partly, this may be a consequence of nuclear proliferation which makes the prospect of a nuclear club with 20 or more members by the end of the century entirely conceivable. Not only do nuclear arms seem destined to spread, but the means of delivering them, quickly and accurately, could also become widely available with the expanding international transfers of modern military airplanes, short-range rocketry, and so forth. Neither these weapons nor the delivery vehicles and their guidance systems will approach the sophistication of the hardware possessed by the two superpowers, but the relevant targets (even those of a military sort) will in this case be much more easily attainable. This implies that the nature of military power, more so perhaps than the extent to which it is balanced, may become a crucial determinant of the likelihood of massive destruction. It is not within the compass of a brief essay to delve very deeply into the myriad issues and scena- rios which this suggests but one, somewhat counterintuitive, point should be made. Specifically, it seems that in a situation of parity, greater preemptive capacity may or may not be destabilizing. Let me explain.

Assume, for example, two nations, each of which possesses sufficient explosive capacity to neutralize the opponent's ability to retaliate if only this could be delivered, accurately, rapidly, and predictably, on target. This will be determined by what we shall call the reliability of the two sides' delivery systems. ${ }^{21}$ That of the prospective attacker can be designated $\mathrm{Ra}$, that of the putative victim $\mathrm{Rb}$; if there is parity, we can set $R a=R b=R$. Under these conditions, which are not far-fetched, an increase in reliability might either encourage or discourage the initiation of warfare. This will be clarified by understanding that the likelihood of the defender's military capacity (i.e., of his retaliatory arsenal) surviving an attack is (1-R) and, if it does survive, the likelihood that it would destroy chosen targets on the attacker's side is, simply, $R$. The overall capacity to launch a successful retaliation will determine the likelihood of deterrence (D) and this is given by the function $D=R(1-R)$, a function which has a maximum when $R$ equals 0.5 . At this point, therefore, the probability of a preemptive strike is minimized while, below or beyond it, it becomes increasingly likely (because the defender's ability to retaliate diminishes on both sides of that point).

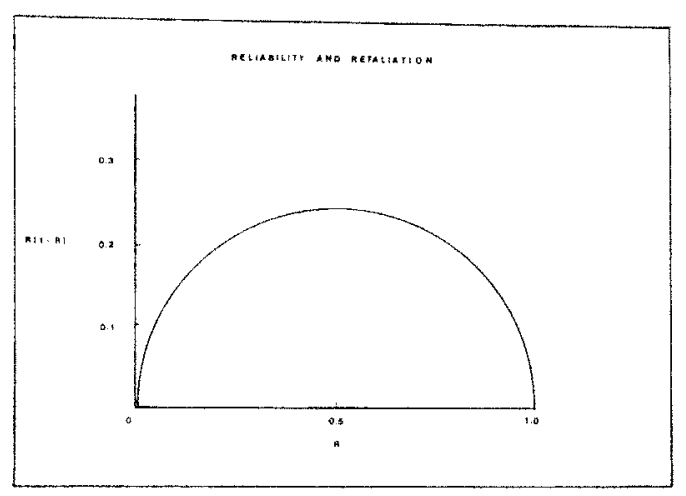


This is but one issue and the purpose of the exercise is merely to demonstrate that the role of military power is more complex than might appear at first glance. Notions of military equilibrium remain important (different conclusions might have been drawn in the preceding example if equal reliabilities had not been assumed), but evolving weaponry calls for more nuanced analyses than have been provided by traditional theories in the discipline). Thus, not only nuclear weaponry but its horizontal proliferation raise conceptual and empirical issues to be more fully addressed by peace resarch.

\section{The current task}

Despite the high hopes which were entertained some years ago it cannot be accurately claimed that we have progressed very far in understanding the causes, forms and implications of international conflict. It is not so much that we have failed to exert ourselves on behalf of our quest but, perhaps, that in our zeal to produce empirical findings we have allowed some fundamental questions to slip out of focus. If this assessment is correct, then the remedy too is obvious: More effort should be invested in building relevant theoretical foundations to buttress and to guide our research. Neither can progress very far without the other: Propositions must be put to rigorous empirical tests, yet the better the propositions the more instructive will be the tests. The status of our theoretical achievements is such that we are somewhat disoriented; nevertheless, there are several potentially fruitful points of departure. My own judgment, as indicated in this essay, is that at least three sets of issues need additional work. The first involves the structure of incentives behind conflictive behavior; starting with the level of simple hostility. Special attention would be devoted hereto the nature and implications of the situations which I have, for lack for a more imaginative terminology, identified as Type 1 and Type 2 . The second area would concern the set of conditions under which incentives to conflictive behavior yield warfare rather than more hostility. The effect of the type of situation which characterizes an attainment gap and the respective rewards produced by either level of conflict should, in particular, be adequately understood. Finally, the role of the evolving nature of military power in determining the probability of war must be traced in greater detail. Peace research as a discipline is not disintegrating; it is, however stultified and an infusion of conceptual vigor seems the appropriate remedy.

\section{NOTES}

1. Two good reviews of some of these findings, published in this journal are J. David Singer, 'Accounting for International War: the State of the Discipline', and WolfDieter Eberwein, 'The Quantitative Study of International Conflict: Quantity or Quality?' Journal of Peach Research, Vol. 17(1), 1981.

2. Barring, of course, the theoretical posibility of an accidental war.

3. I am not equating dissatisfaction with the psychological concept of frustrations.

4. The classical statement of this perspective is, of course, Hans H. Morgenthau, Politics Among Nations (New York: A. A. Knopf), 1967, fourth edition.

5. See, for example, Harold Kelley, 'Two Functions of Reference Groups', in Guy E. Swanson, ed. Readings in Social Psychology (New York: Holt, 1952), Robert K. Merton, Social Theory and Social Structure (Glencoe: The Free Press, 1957). For a practical application, see Jack Nagel, 'Inequality and Discontent: A Nonlinear Hypothesis', World Politics, July, 1975.

6. This perspective is represented in Gerhard Lenski, 'Status Crystallization: A Non-vertical Dimension of Social Status', American Sociological Review, 19, 1954. Also, Johan Galtung, 'A Structural Theory of Aggression', Journal of Peace Research, 2, 1964.

7. See James C. Davies, 'Toward a Theory of Revolution', American Sociological Review, February 1962.

8. The size of the gap would be the level of attainment itself, and the algebraic sign of the gap would be positive only if it involved a 'bad' (for the bad 'sickness', for example, a zero level of attainment, or normal health', would seem to be the natural referent).

9. Georg Simmel, Conflict and the Web of Group Affiliation (Glencoe: The Free Press, 1955) and Lewis A. Coser, The Functions of Social Conflict (Glencoe: The Free Press, 1956).

10. For example, Quincy Wright, A Study of War, abridged edition (Chicago: University of Chicago Press, 1965), p. 169.

11. For a study of international warfare which takes the pursuit of natural resources into explicit account, see Nazli Choucri and Robert North, Nations in Conflict: 
National Growth and International Violence (San Francisco: W. H. Freeman, 1975).

12. See, for example, Inis L. Claude, Jr., Power and the International System (New York: Random House, 1969) and A. F. K. Organski, The War Ledger (Chicago: University of Chicago Press, 1980). For a somewhat different twist on this subject, see Geoffrey Blainey, The Causes of War (New York: The Free Press, 1973).
13. See George Quester, Offense and Defense in the International System (New York: John Wiley and Sons, 1977).

14. Ibid., p. 156.

15. This is argued more fully in Miroslav Nincic, The Arms Race: the Political Economy of Military Growth, forthcoming (New York: Praeger, 1982), chapter 5. 